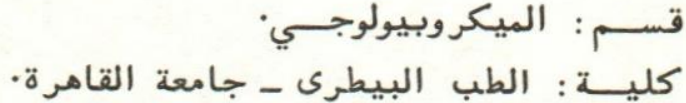

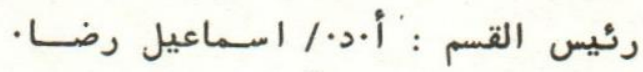

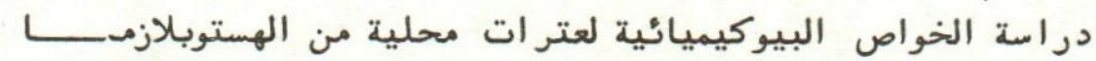

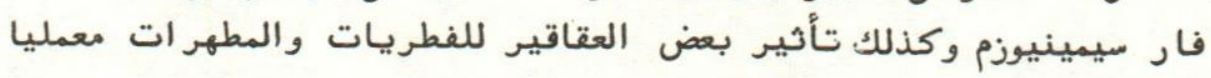

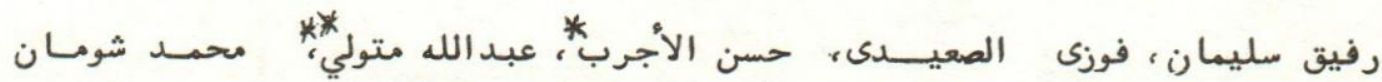

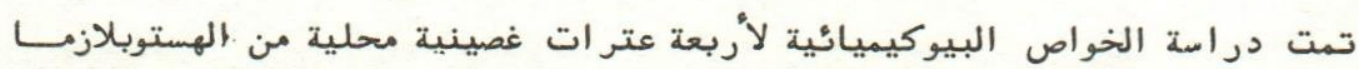

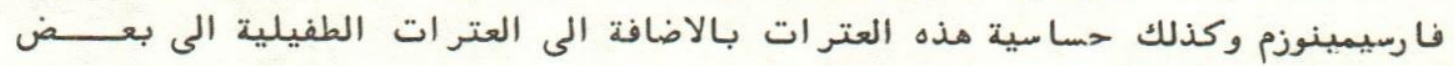

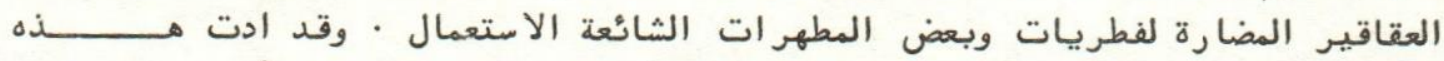

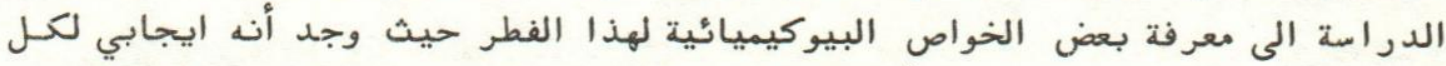

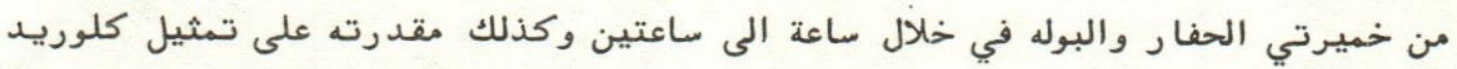

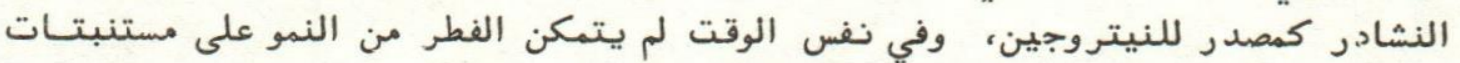
السكريات والنتر ات و والجيلاتين ولنين وفين

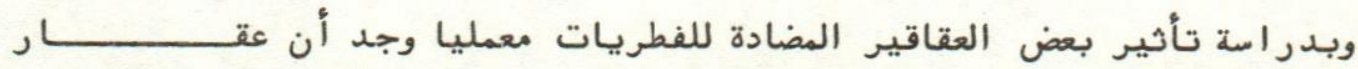

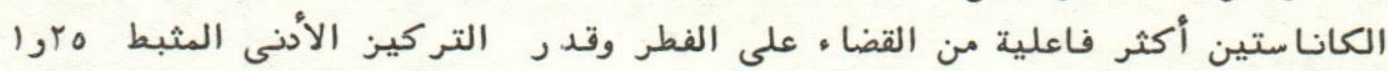

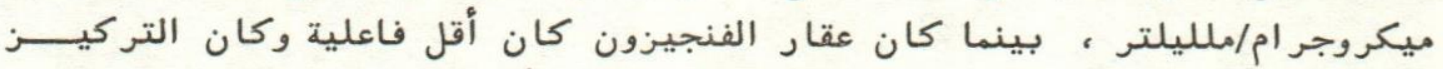

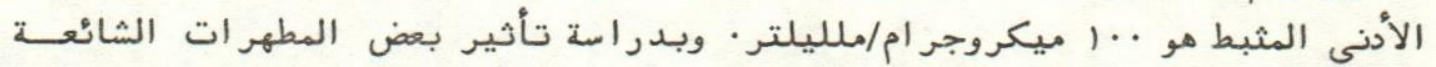

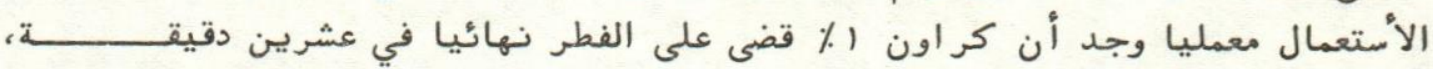

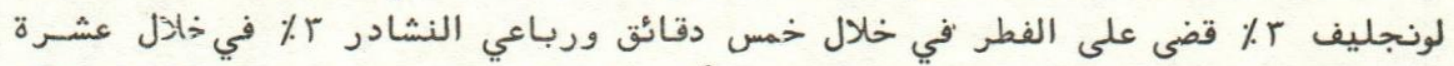

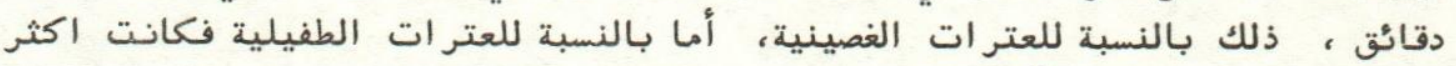

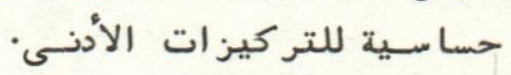

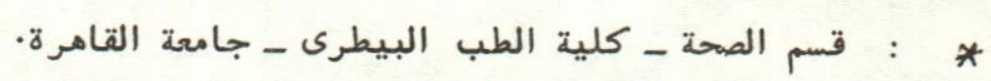

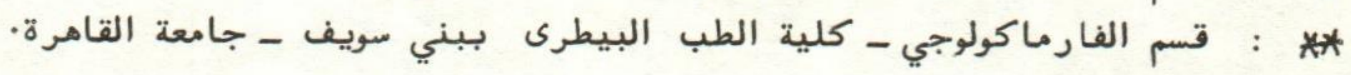


Dept. of Microbiology,

Fac. of Vet. Med., Cairo University,

Head of Dept. Prof. Dr. I. Reda.

\title{
STUDIES ON HISTOPLASMOSIS FARCIMINOSSII \\ ( EPIZOOTIC LYMPHANGITIS ) IN EGYPT \\ IV- The biochemical characters of local isolates of \\ Histoplasma Farcimonosum and their sensitiity \\ to antimycotic and disinfectants in vitro \\ (With 4 Tables)
}

\author{
By \\ R. SOLIMAN; F.R. EL-SEEDY; H. EL-AGRAB*; \\ A.M. EL-BAUOMY** and M.T. SHOUMAN \\ (Received at 30/7/1986)
}

\section{SUMMARY}

\begin{abstract}
The biochemical activities of the mycelial form of 4 locally isolated strains of Histoplasma farciminosum were identical, they were catalase positive, urease positive within 1-2 hours and could assimilate ammonium chloride as a sole source of nitrogen. At the same time, there was no growth on sugars, nitrate and gelatine media even after 6 weeks inculation at $25^{\circ} \mathrm{C}$ or $37^{\circ} \mathrm{C}$.

The sensitivity of both yeast parasitic and mycelial cultural forms to diferent dilutions of 4 types of antimycotic drugs in dextrose-glycerol-PPLO media revealed that Canestin was the most effective drug and the Minimal Inhibitory Concentration (M.l.C.) on both forms was $1.25 \mathrm{ug} / \mathrm{ml}$. On contrary fungizone showed the least activity with M.l.C. of $100.0 \mathrm{ug} / \mathrm{ml}$ for both forms.

Regarding the effeciency of the commonly used disinfectants, it was found that $1 \%$ Crown for 20 minutes, 3\% Longlife for 5 minutes and 3\% Quanternary Ammonium for' 10 minutes were effective in vitro on the mycelial cultural form. On the contrary, the yeast parasitic form was more sensitive to a lower concentration, where $0.5 \%$ of Crown and Longlife were effective after 5 minutes application in vitro.
\end{abstract}

\section{INTRODUCTION}

Egypt as a mediterranean country was considered as an endomic area for Epizootic Lymphangitis infection of equines. Several cases of histoplamosis have been recorded in Egypt (KHATER et al., 1968; REFAI and LOOT, 1970). Moreover, FOUAD et al. (1973) and EL-GUINDI

* : Dept. of Hyigene, Fac. Vet. Med., Cairo University,

** : Dept. of Pharmacology, Fac. of Vet. Med., Beni-Suef, Cairo University.

Assiut Vet. Med. J. Vol. 17, No. 34, 1986. 


\section{R. SOLIMAN, et al.}

et al. (1975) reported lachrymal and conjunctival infections among donkeys in Lower and Upper Egypt. RECENTLY, SELIM et al. (1985) recovered 4 isolates of Histoplasma farciminosum from five horses in Helwan district near Cairo showing typical signs of Epizootic Lymphangitis (African Farcy). The colonies of the mycelial form appeared within 4-6 weeks on dextrose-glyerol-PPLOagar as yellow, light brown to deep brown waxy cauliflower-like growth.

The aim of this work is to study the biochemical characters of the 4 locally isolated Histoplasma farcimonosum strains. At the same time their sensitivity to some antimycotic drugs and commonly used commercial disinfectants was evaluated in vitro as a primary trials for controlling the spread of the infection in Egypt.

\section{MATERIAL and METHODS}

The recovered 4 isolates of Histoplasma farciminosum from Egyptian horses (SELIM et al., 1985) were coded in the Department of Microbiology and Immunology, Faculty of Vet. Medicine, Cairo University, Giza/Egypt as follows; 8301/8920, 8301/8922, 8301/8924 and 8301/ 8926.

The 4 isolates were recultivated on $2 \%$ dextrose- $2.5 \%$ glycerol-PPLO-agar (SELIM et al., 1985) for examination of their sensitivity to antimycotic drugs and disinfectants, while the parasitic yeast forms were obtained from the 4 exudates of 4 infected horses.

The biochemical activities of the mycelial form of the four isolates were identified by the application of the following tests:-

1- Fermentations of sugars (glucose, sucrose, maltose, galactose and fructose) using sugar fermentation media (CRUICKSHANK et al., 1975).

2- Assimilation of ammonium compounds (chloride, sulphatce and nitrate).

3- Utilization of citrate using Simon's citrate media.

4- Hydrolysis of urea on Christensen's urea media (CHRISTENSEN, 1946).

5- Nitrate reduction test.

6- Catalase test.

7- Liquefication of gelatin (CRUICKSHANK et al. 1975).

The inoculated media (two sets) were incubater for $4-6$ weeks at $25^{\circ} \mathrm{C}$ (room temperature) and $37^{\circ} \mathrm{C}$ with periodic examination. Catalse test was applied by adding few drops of hydrogen peroxide (one volume) to the growing colonies. The antimycotic activity of the following drugs: Canestin/Bayer (Bis-phenyl 2-chlorophenyl 1-imidiozolyl-methans), Grisofulvin/ Kahira (Kahira Pharmaceticals and Chemical, in tablets $125 \mathrm{mg} / \mathrm{Tab}$.), Fungizone/Squibb (Amphotericin-B in tablets $50 \mathrm{mg} / \mathrm{Tab}$.) and Mycostatin/Squibb (Nystatin in 100.000 Unit/caps) were examined on both forms. The first three drugs were added to the dextrose-glycerol-PPLO-agar in 14 concentrations (Table 1) started from $0.025 \mathrm{ug}$ to $1000 \mathrm{ug} / \mathrm{ml}$ media except Mycostatin which is available in units. Examination of the antimycotic action was applied according to RIPPON (1982) to detect their inhibitory effect with determination of the minimal inhibitory concentration (M.l.C.) or dose. The growth or its inhibition was observed daily for 8 weeks of incubation at $25^{\circ} \mathrm{C}$ and $37^{\circ} \mathrm{C}$.

For determination of the action of disinfectants on the growth of both forms of H.farciminosum in vitro, two loopfull of the 4 exudates i.e. parasitic form as well as parts of the 


\section{HISTOPLASMOSIS FARCIMINOSSI}

mycelial form were inoculated seperately onto $2 \mathrm{ml}$ dilutions $(0.5,1,2,3,4$ and $5 \%$ ) of the following disinfectants; Crown (lodophore Compound, Fa. Crown Chem. Com. Ltd. UK)., Longlife (Antec. A.H. International Ltd. England), Prophyl (Meriel Lab., France) and Quanternary Active Sterilizer (Quanternary Ammonium, Fa. Antec. A.H. International Ltd. England). After inoculation; the two fungal forms were left under the effect of each disinfectant for the following exposure times; 5, 10, 40 and 80 minutes as well as 24 hrs at room temperature (Tables 2 \& 3). The effect of each dilution under the various exposure times was evaluated by the heavy inoculations of two sets of glucose-glycerol-PPLO-slant with the treated forms, then incubated at room temperature $25^{\circ} \mathrm{C}$ and $37^{\circ} \mathrm{C}$ with daily observation up to $6-8$ weeks.

\section{RESULTS}

The biochemical characters of the four isolates of mycelial form of Histoplasma farciminosum were almost identical. The results of the effect of different dilutions of four antimycotic drugs on Histoplasma farciminosum are indicated in Table (1). Also, serial dilutions of four commonly used disinfectants were tried on both mycelial and parasitic forms for different periods (Tables 2 \& 3). The parasitic and mycelial forms of Histoplasma farciminosum are equally sensitive to the same doses of three antimycotic drugs, (Table 4).

Table (1)

Determination of minimal inhibitory concentration (M.I.C.) of antimycotic drugs on mycelian (M.) and parasitic ( $P$ ) forms of $\underline{H}$. farciminosum.

\begin{tabular}{|c|c|c|c|c|c|c|c|c|}
\hline \multirow{3}{*}{$\begin{array}{l}\text { Drug } \\
\text { dilution } \\
\text { ug/ ml }\end{array}$} & \multicolumn{8}{|c|}{ Growth on glucose-glyceral PPIO-media containing } \\
\hline & \multicolumn{2}{|c|}{ Canestin } & \multicolumn{2}{|c|}{ Mycostatin } & \multicolumn{2}{|c|}{ Grisofulvin } & \multicolumn{2}{|c|}{ Fungizone } \\
\hline & M & $P$ & M & $\mathrm{P}$ & M & $P$ & M & $\mathrm{P}$ \\
\hline 0.025 & + & + & + & + & + & & + & + \\
\hline 0.05 & + & + & + & + & + & + & + & + \\
\hline 0.1 & + & + & + & + & + & + & + & + \\
\hline 0.5 & + & \pm & + & + & + & + & + & + \\
\hline 1.25 & - & - & + & + & + & + & + & + \\
\hline 2.5 & - & - & - & + & + & + & + & + \\
\hline 5.0 & - & - & - & - & \pm & \pm & + & + \\
\hline 12.5 & - & - & - & - & - & - & + & + \\
\hline 25.0 & - & - & - & - & - & - & + & + \\
\hline 50.0 & - & - & - & - & - & - & + & + \\
\hline 100.0 & - & - & - & - & - & - & - & - \\
\hline 250.0 & - & - & - & - & - & - & - & - \\
\hline 500.0 & - & - & - & - & - & -- & - & - \\
\hline 1000.0 & - & - & - & - & - & - & - & - \\
\hline
\end{tabular}

Assiut Vet. Med. J. Vol. 17, No. 34, 1986. 
R. SOLIMAN, et al.

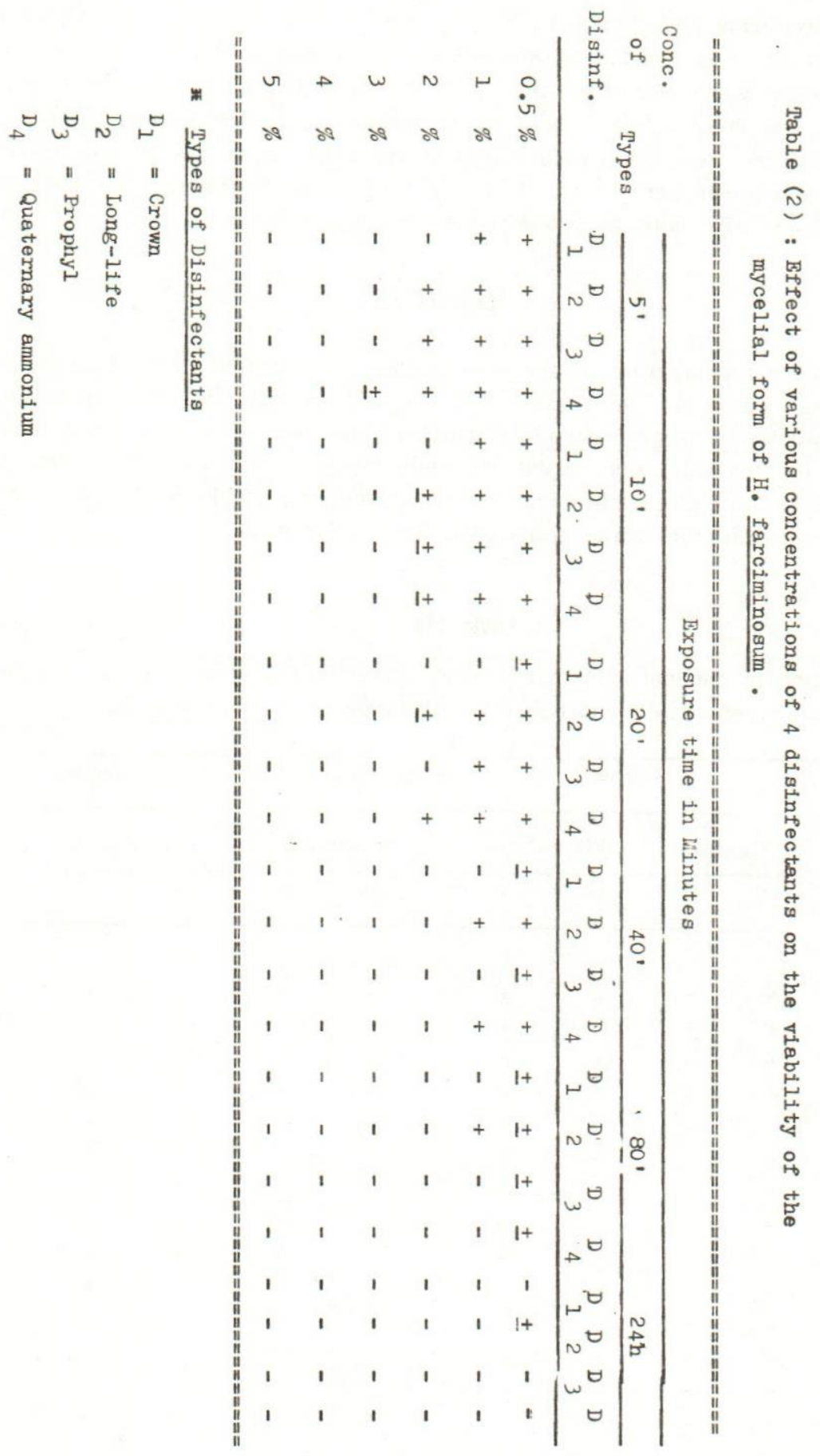


HISTOPLASMOSIS FARCIMINOSSI

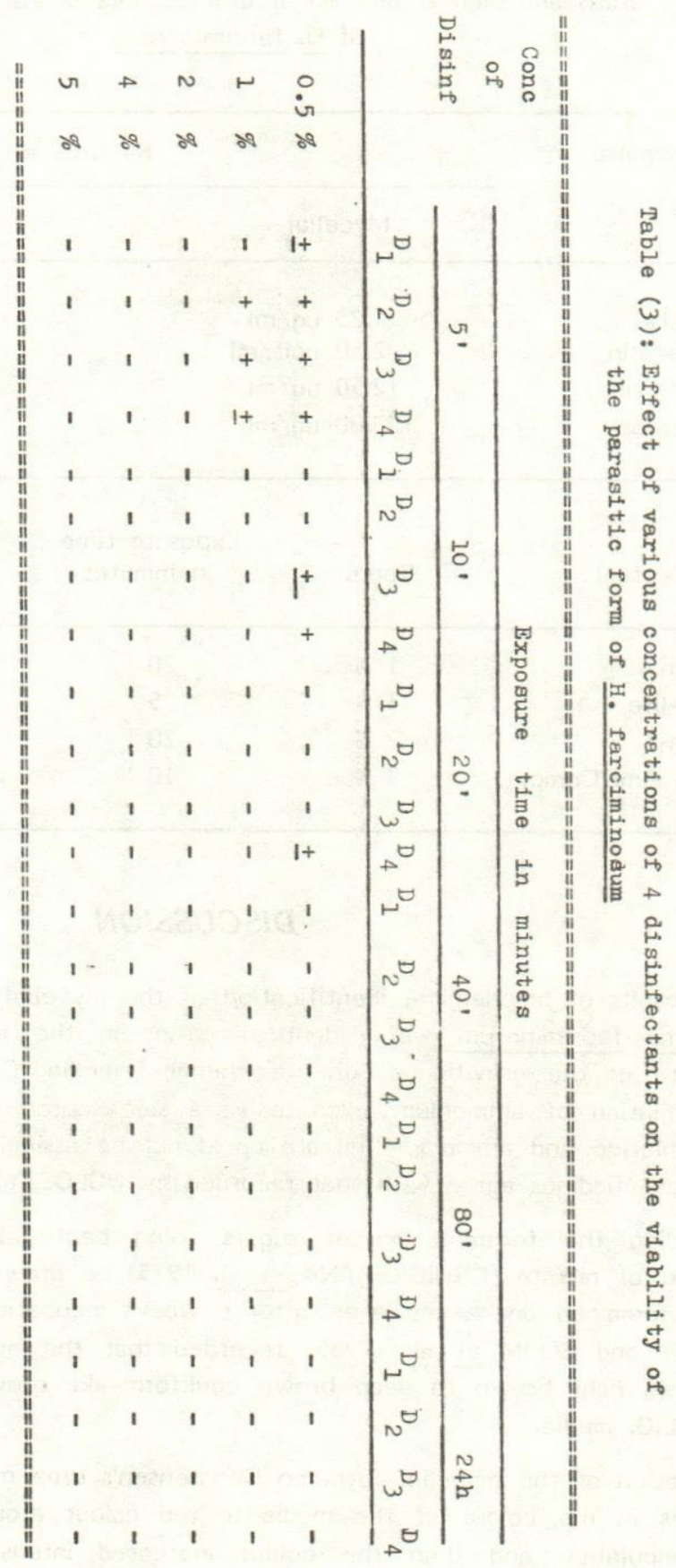

Assiut Vet. Med. J. Vol. 17, No. 34, 1986. 


\section{R. SOLIMAN, et al.}

Table (4)

Conclusive table on Minimal Inhibitory Concentrations (M.I.C.) of antimycotic drugs and highest dilution of disinfectants affeting both farms of $\mathrm{H}$. farciminosum.

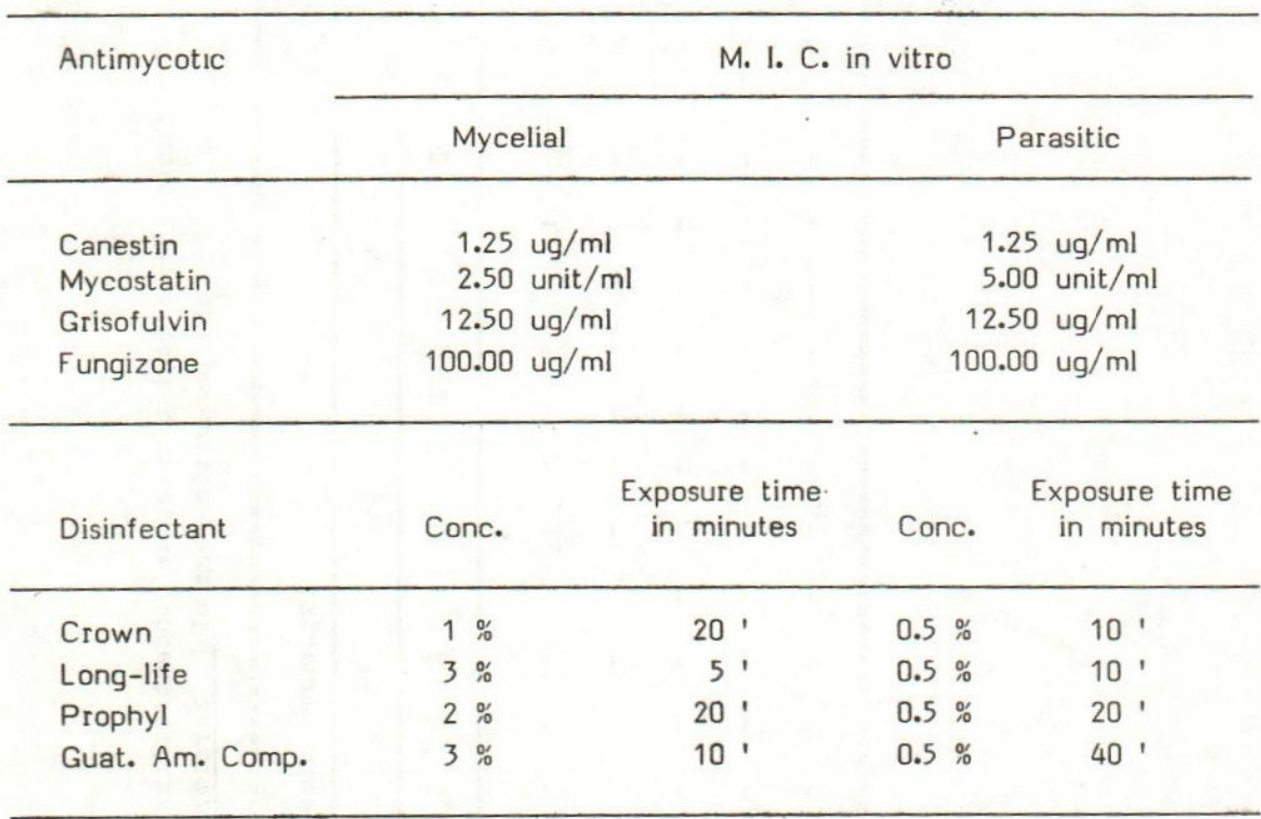

\section{DISCUSSION}

The results of biochemical identification of the mycelial cultural form of the four isolates of Histoplasma farciminosum were identical either in the rapidity in the urease production or the failure of the growth on some biochemical media. Catalase test was positive as well as the assimilation of ammonium sulphate as a sole source of nitrogen. On the other aspect ammonium chloride and ammonium nitrate could not be assimilated by the 4 isolates of $\underline{H}$.farciminosum. These findings agree with that recorded by WOLOSZYN (1968).

Regarding the fermentation of sugars using bacterial media, liquefication of gelatin, and reduction of nitrate (CRUICKSHANK et al. 1975) no growth could be noticed as the inoculated media remained unchanged even after $\frac{6}{6}$ weeks incubation at $25^{\circ} \mathrm{C}$ or $37^{\circ} \mathrm{C}$. ABOU-GABAL et al. (1983) and SELIM et al. (1985) recorded that the growth of H.farciminosum appeared as a yellowish, light brown to deep brown cauliform-like growth within 4-6 weeks on glucoseglycerol P.P.L.O. media.

Cultivation of the mycelial form on Christensen's urea media (CHRISTENSEN, 1946) showed rapid changes in the colour of the media to red colour around the inoculate within only one hour post-inoculation and then the colour increased intensively within the following hours. Such observation required more intesive comparative investigations with the other histoplasma species to be applied or recommended as a rapid identification character.

The impact of epizootic lymphangitis in the endemic areas as in Egypt is a serious problem in veterinary public rules on one side and as a cause of economic losses on the other side.

Assiut Vet. Med. J. Vol. 17, No. 34, 1986. 


\section{HISTOPLASMOSIS FARCIMINOSSI}

Infection of highly expensive arabian horses caused a great losses. From this point trials to examine the effect of some newly introduced antimycotic drug in vitro may throw light to dissolve such problem. The detailed results of the effect of 14 dilutions of 4 antimycotic drugs added to glucose-glycerol-P.P.L.O. media are indicated in Table (1). The effective M.I.C. that inhibit completely the growth of parasitic yeast form varied to some extent from that of mycelial form. It was noticed that the mycelial form was slightly sensitive as in case to Mycostatin (2.5 unit/ml for mycelial form and 5.00 unit/ml for parasitic form). Canestin was the most effective antimycotic drugs as its M.l.C. for both torms were the same $(1.25 \mathrm{ug} / \mathrm{ml})$. The M.l.C. of Grisofulvin for both forms were relatively higher $(12.5 \mathrm{ug} / \mathrm{ml})$ for each. Elsewhere Fungizone was less effective as a relatively higher concentration are required to inhibit the growth $(100.00$ $\mathrm{ug} / \mathrm{ml}$ ). This results agreed to some extent with the finding of RIPPON (1982) who treated histoplasma-infection with Amphotericin B and Hamycin. He concluded that the yeast form was quite sensitive to Hamycin in vitro.

ABOU-GABAL and HENNAGER (1983) stated that the initial source of histoplasmosis infection may originate from the soil as the causative agent probably reach the host through skin abrasions and insect bites. The nodular lesions of this disease develop unnoticed specially on the exterimities of the animal and continue to disseminate the organism in the surrounding. According to this fact, disinfectant should be tried to mirrimize as far as possible the spread of infection. In this work serial dilutions of 4 commonly used disinfectants were tried on both the mycelial cultures and exudates contained the parasitic form for different periods (Tables 2 \& 3). The results showed that the parasitic form could be killed after 10-20 minutes exposure by $1 \%$ concentrations of the 4 types, while the mycelial form did not affected by such concentration and killed by $2 \%$ concentration. The most effective means of disinfection were $1 \%$ Crown within 20 minutes and $3 \%$ Longlife within 5 minutes exposure (Table 2, 3 \& 4). On the other hand the use of disinfectants for more than 40 minutes was of unpractical value. LINTON (1965) claimed that the periodical and regular application of disinfectants in the contaminated environment and animal fomites as grooming tools and clothing may minimize the incidence of H.farciminosum infection among horses. Also MAGDOLNA and KOHALMI (1981) reported that the chain of infection could be interupted by inensive distinfection as a preventive measures to control the spread of the disease.

In conclusion, it was noticed that the parasitic and mycelial forms of Histoplasma farciminosum are equally sensitive to the same doses of 3 antimycotic drugs, while the mycelial forms are relatively resistant to the action of disinfectants (conclusive table 4). From the obtained results it is clear that canestin is the drug of choice iro chemotherapy of infected horses and the disinfection of the stables could be at the best made using crown.

\section{REFERENCES}

Abou-Gabal, M.A. and Henager, S. (1983): Study on the survival of Histoplasma farciminosum in the environment. Mykosen 28(9) 481-484.

Abou-Gabal, M.A., Hassan, F.K.; Al-Said, A.A. and Al-Karim, K.A. (1983): Study on Equine Histoplasmosis "Epizootic lymphangitis". Mykosen 26 (3) 145-151.

Christensen, W.S. (1946): Urea decomposition as a mean of differentiating proteus and pracolon cultures from each other, from salmonella and shigella types. J. Bact 52, 461-466.

Cruickshank, R.; Duiguid, J.P.; Marmion, B.P. and Swain, R.H.A. (1975): Medical Microbiology. 12th Ed., Churchill Livingstone, Edinbrugh London New-York.

El-Guindi, M.H.; Shckeir, A.A.; Wasfey, I.A. Ahmed, K.K.; Elbedewy, A.; Abou-Gabal, M. and El-Rehewy, M.S. (1975): Histoplasmosis of the eyes of donkeys. II- An electron microscopic study. Assiut Vet. med. J. 2, 235-239.

Assiut Vet. Med. J. Vol. 17, No. 34, 1986. 


\section{R. SOLIMAN, et al.}

Fouad, K.; Saleh, M.S.; Sokkar, Soheir and Shouman, M.T. (1973): Studies on lachrymal histo-. plasmosis in donkeys in Egypt. Zbl. Vet. Med. B, 8, 584-593.

Khater, A.R.; Eskander, M. and Moustafa, A. (1968): A histopathological study of cutaneous lesions in equine histoplasmosis "Epizootic Lymphangitis". J. Egypt. Vet. Med. Ass. $28,165-174$.

Linton, R.G. (1965): Veterinary Hygiene. Scientific Book Agency Calcutta, Indian.

Magdolna, S. and Kohalmi, I. (1981): Endemic Trichophyton mentagrophytes infection of rabbit origin. mykosen 24 (7) 412-420.

Refai, M. and Loot, A. (1970): Incidence of epizootic lymphangitis in Egypt with reference to its geographical distribution. Mykosen 13 (5) 247-252.

Rippon, J.W. (1982): Medical Mycology. Chapter of the Pathogenic Fungi and the Pathogenic Actinomycetes. 2nd Ed., W.B. Saunders Gompany, Philadelphia, USA, P. 782-786.

Selim, S.A.; Soliman, R.; Osman, Kamelia; Padhye, A.A. and Ajello, L. (1985): Studies on Histoplasmosis Farciminosii "Epizootic Lymphangitis" in Egypt. Eur. J. Epidemiol., 1 (2), 84-89.

Waloszyn, S. (1968): Investigations into the properties and antigenic structure of H.farciminosum II- Biochemical propeties. IV- Evaluation of sensitivity to some antimycotic substances. Medycyna Wet. 24, 140-143; 212-214: 